\title{
Need for a Holistic Approach in Successful Implementation of Select Modern Concepts and Developments in Agronomy
}

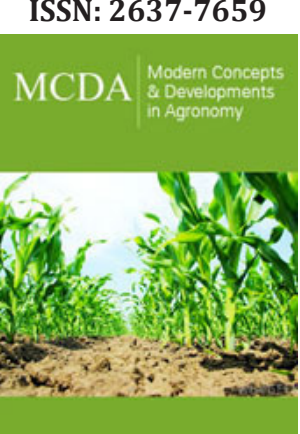

*Corresponding author: Dr.P.R.Reddy, Former Director Grade Scientist, CSIRNGRI, Hyderabad-500 0007, India

Submission: 啙 May 31, 2019

Published: 海 June 06, 2019

Volume 4 - Issue 3

How to cite this article: Parvata Reddy. Need for a Holistic Approach in Successful Implementation of Select Modern Concepts and Developments in Agronomy. Mod Concep Dev Agrono.4(3). MCDA.000590.2019.

DOI: 10.31031/MCDA.2019.04.000590

Copyright@ Parvata Reddy, This article is distributed under the terms of the Creative Commons Attribution 4.0 International License, which permits unrestricted use and redistribution provided that the original author and source are credited.
Dr. P. R. Reddy*

Former Director Grade Scientist, CSIR-NGRI, Hyderabad-500 0007, India

\section{Opinion}

Man, always strives to achieve something better to make his life less tedious and more enjoyable, irrespective of such activities negative impact on environment and other species. Researchers and economic experts belonging to mid-20 $0^{\text {th }}$ century have set aside ageold traditional agriculture. Present day researchers believe that a mixture of traditional agriculture and new technology-based agriculture is needed, giving importance to area specific environmental set up. Any new initiative can yield better results if the researcher understands, before putting into practice his ideas, the limitations and positive aspects of his planned new research and developmental strategy. With population growing exponentially, with no restrictions of effective nature in practice in any part of the globe new methodologies are to be developed to ensure food security to billions of human beings and various species that depend on the natural resources that are fast depleting, through a holistic approach. The holistic approach succeeds only if research carried out by a research organization makes use of global status of applicability of such a research through open access interaction with peers in this research field. In achieving such a growth, the Journal-Modern Concepts \& Developments in Agronomy by Crimson Publishers is launching a new volume, an initiative worth apt support by the scientific community and planning \& administrative experts of different countries. I deem it a privilege to write an Editorial, which is aimed at introducing both the experts and knowledgeable administrators the various aspects of this positive initiative.

Even though there are number of standard topics in Modern Concepts in Crop Production and proper utilization of the produced yield, especially when there are number of books on new technology in agronomy, I opine some topics need a special place and reference in the new volume. I recommend such an approach as agriculture in the recent times is negatively impacted by Global warming and Climate change. Global warming impact is significant on crop growth and environment, as such, concept of ideal plant type and crop modeling for desired crop yield through apt Scientific principles of crop production by adapting Integrated farming systems need focus. Also, resource conservation technology leading to precision agriculture need to be covered in this volume. As plant growth basically depends on water and soil fertility it is essential to focus on these two important topics. With Global warming reaching an alarming state, leading to unpredictable monsoon variability efforts are to be made to optimally utilizing both surface and subsurface water resources, selecting micro to major irrigation facilities by ensuring proper storage facilities after filtering out pollutants introduced by human beings. This aspect needs to be given importance in the volume. If possible it is necessary to bring out the importance of wetlands in safeguarding / rehabilitating lakes, tanks and ponds. Soil fertility is crucial to plant growth. With overuse of chemical fertilizers and pesticides we have degraded soil quality. In situ availability of natural resources helps us to produce good quality fertilizers and pesticides. Since soil fertility improvement takes some time, in the first year one has to grow crops that are pest resistant and survive using in situ availability of natural fertilizers. Research in the recent times has come out with excellent results by replacing standard cereals like rice and wheat with millets. Also, research has helped in growing saline resistant rice. This is a major breakthrough, as coastal ecology 
is significantly disturbed by increase of sea surface temperature and resulting polar ice melting leading to sea surface rise. This is causing saline water incursion making fertile lands saline. In such lands saline resistant rice can lessen the losses, helping farmers. Important success stories, as case studies, will enhance the quality of the volume. In this volume it is essential to include research findings covering Integrated farming systems, organic farming, dry farming and determining the nutrient needs for yield potentiality of crop plants. Rotation of cropping pattern is essential to retain nutrient richness of soil, following a combination of traditional and modern technologies. There is no dearth of information covering various topics. But these details will be of immense use only when area specific methodologies are included. So, the volume should give importance to case studies.
Since everyone`s final goal is food security and lessening the pain of poverty-stricken millions, agriculture remains an important if not dominant part of most developing countries' economies and is the most likely source of significant economic growth and reduction in poverty. As such, I do believe, this aspect will be covered properly in the volume. As pointed out by Dinesh Kumar and Shivay (2008) the positive impact of new initiatives for durable growth of better livelihood of millions of poor, importance of agriculture - and related rural enterprise-should become a livelihood strategy for hundreds of millions of the world's poorest people and can have a major impact on the environment. Well-managed, agriculture can enhance livelihoods, conserve soil and water resources, preserve trees and biodiversity, and contribute to the locking of carbon. 